\title{
Integração Numérica com Auxílio do Software Geogebra
}

\author{
Maria Janete de M. Albuquerque Merian O. Nascimento \\ Mauro Alex F. Bentes* Arthur da C. Almeida \\ Faculdade de Matemática, CUNCAST, UFPA \\ 68746-360, Castanhal, PA \\ E-mail: janetecap@hotmail.com, limamerian@gmail.com, mauro.bentes@castanhal.ufpa.br, \\ arthur@ufpa.br
}

\section{RESUMO}

O uso de softwares na educação é uma das tendências para melhorar o ensino por meio das TIC's (Tecnologias da Informação e Comunicação), tendo como objetivo apresentar uma alternativa no ensino da Matemática, especialmente, no Cálculo Diferencial e Integral, disciplina tradicionalmente considerada como muito difícil, buscando melhor compreender, de forma visual, os conceitos abstratos dessa disciplina.

As aulas práticas no Laboratório de Informática podem incentivar os alunos no aprendizado do conteúdo, pois os possibilitam a interagirem com o computador e visualizarem o resultado desta interação, além de permitir explorar outras facetas da matemática. Existem inúmeros softwares matemáticos, alguns de domínio público e outros proprietários, que podem ser utilizados na disciplina de Matemática. Um dos que se mostraram interessantes foi o software de Geometria Dinâmica Geogebra que além de ser livre e de fácil familiarização por parte de alunos e professores, é possível realizar testes sucessivos, o que facilita o poder de investigação pelo dinamismo [2]. É gratuito, em português e permite simular construções geométricas bidimensionais que despertam mais interesse e atenção, contribuindo assim para uma aprendizagem significativa, na qual serão necessárias que os alunos já tenham conhecimentos teóricos e utilizem os softwares apenas como ferramentas auxiliares e complementares.

Um dos conceitos que se presta muito bem para ilustrar o uso desse tipo de ferramenta computacional é o de Integral Definida abordando a formulação de Riemann ou RiemannDarboux, que consiste em dividir um intervalo fechado em subintervalos e depois variar o seu tamanho tornando-os suficientemente pequenos para que se possa visualizar o efeito tanto na soma superior (que diminui) como na soma inferior (que aumenta). Com uma animação gráfica no Geogebra pode-se simplificar o entendimento deste conteúdo, pois facilita visualizar as áreas dos retângulos e ainda perceber numericamente que a soma se aproxima do valor da área total à medida que se aumenta o número de retângulos.

Para a integração numérica, o Geogebra apresenta diversas opções como soma de Riemann à esquerda, inferior, superior e trapezoidal (Simpson). No exemplo a seguir, será utilizada a soma de Riemann inferior.

Na Figura 1, na janela (a) do Geogebra, ao lado esquerdo, pode ser observado o gráfico da função $\mathrm{f}(\mathrm{x})=\operatorname{sen}(\mathrm{x})$, o intervalo $[0, \pi]$ dividido em 10 subintervalos, sendo a soma inferior das áreas dos 10 retângulos igual a 1,66936, e na janela (b) à direita o mesmo intervalo dividido em 100 subintervalos onde a soma inferior das áreas dos 100 retângulos é 1,96842 aproximando-se cada vez mais do valor exato da integral definida que é igual a 2. 


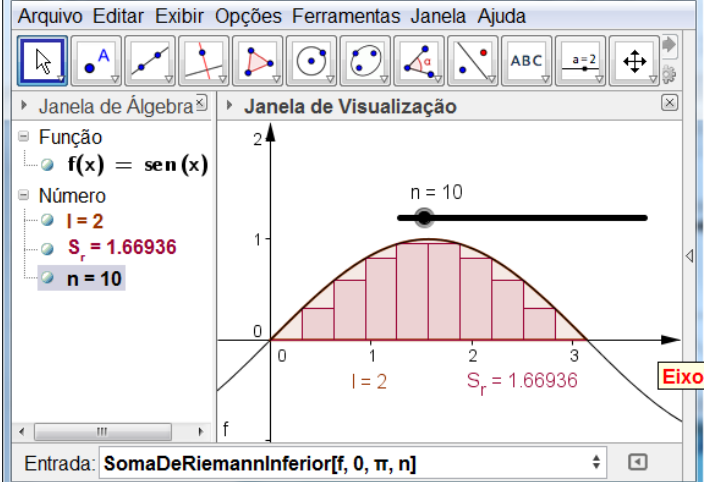

(a) com 10 subintervalos

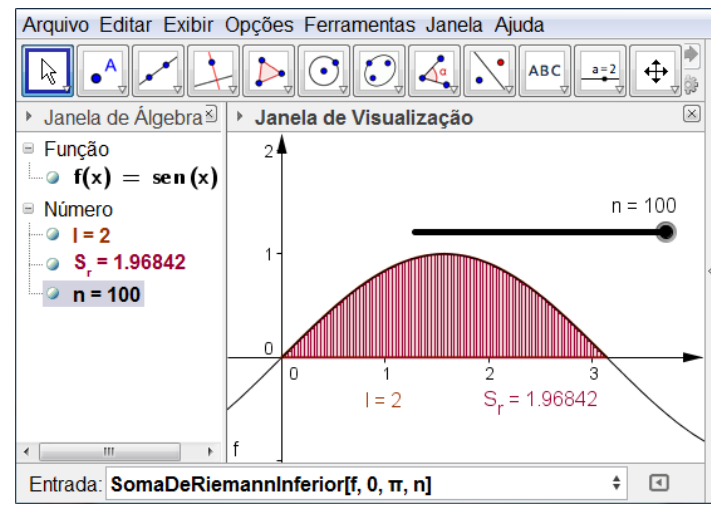

(b) com 100 subintervalos

Figura 1 - Aproximação da Integral definida pela soma inferior de retângulos da área sob uma curva.

À medida que o número de retângulos cresce muito o erro torna-se muito pequeno e assim a soma das áreas retangulares inferiores aproxima-se cada vez mais da área sob a curva de $\mathrm{f}(\mathrm{x})$.

Portanto, o uso do software Geogebra pode auxiliar no ensino de Integração numérica e a prática de atuação docente fica de forma diferenciada. A partir da utilização dessa ferramenta pode se trabalhar vários conteúdos para construir e analisar os gráficos de funções aplicando as definições por meio do dinamismo do software, assim os alunos podem compreender a importância desse recurso no ensino da matemática com o avanço das tecnologias.

Palavras-chave: GeoGebra, Integral, Ensino, Matematica

\section{Referências}

[1] L. A. F. Baldini, M. C. C. T. Cyrino, "O Software Geogebra na Formação de Professores de Matemática - Uma visão a partir de Dissertações e Teses", RPEM, Campo Mourão, Pr, v.1, n.1, jul-dez. (2012).

[2] F. Amorim, G. Sousa, Experiência de Atividade Sobre Integral Utilizando o Software Geogeobra, em "II Congresso Internacional de Educação Cientifica e Tecnológica", URI, Santo Ângelo, 2012.

[3] G. B. Thomas, "Cálculo", 10.ed, São Paulo, Addison Wesley, 2002. 